\title{
Salmonella paratyphi spondylitis: a case report
}

\author{
Pradeep Kumar · Seyed Mohsen Mahmoodi • \\ Nooruddin Kalaparambil Moosa • Michael Edgar · \\ Hussain Al Samt $\cdot$ Riyaz Amirali Hussain
}

Published online: 28 February 2008

(C) Springer-Verlag 2008

\section{Erratum to: Eur Spine J}

\section{DOI 10.1007/s00586-007-0536-2}

This article was mistakenly published under the category "Letter to the Editor". The correct category is "Case Report".

The online version of the original article can be found under doi:10.1007/s00586-007-0536-2.

P. Kumar $(\bowtie) \cdot$ S. M. Mahmoodi · N. Kalaparambil Moosa · M. Edgar

Orthopedic Department, Dubai Hospital,

DOHMS, P.O. Box 7272, Dubai, UAE

e-mail: pkthammanassery@dohms.gov.ae;

malaikamenon@yahoo.com

H. A. Samt · R. A. Hussain

Microbiology Department, Dubai Hospital,

DOHMS, P.O. Box 7272, Dubai, UAE 